Journal of Engineering and Applied Sciences 14 (Special Issue 5): 8912-8920, 2019

ISSN: $1816-949 \mathrm{X}$

(C) Medwell Journals, 2019

\title{
Comparison of Student Team Achievement Division and Team Accelerated Instruction on Student's Achievement in Secondary School Quantitative Economics Contents
}

\author{
Njideka Dorathy Eneogu, Jovita Chinelo Ejimonye, Benedict Ejiofor Ugwuanyi and \\ Ifeyinwa A. Nji \\ Department of Social Science Education, University of Nigeria, Nsukka, 410001 PMB, \\ Enugu State, Nigeria
}

\begin{abstract}
The study compared the effects of Student Team Achievement Division (STAD) and Team Accelerated Instructional (TAI) techniques on student's achievement in secondary school quantitative economics contents. Three research questions and three null hypothesis guided the study. The design adopted for the study was quasi-experimental non-equivalent pre-test, post-test control group design. Sample for the study consisted of 186 SS II students made up of 65 males and 121 females drawn from four co-educational schools in Nsukka Local Government Area of Enugu State. Purposive sampling was used to select the four co-educational schools and two intact classes were randomly sampled from each of the schools. The schools were assigned to the two experimental groups (STAD and TAI). Quantitative Economics Achievement Test (QEAT) was used for data collection. The instrument was face and content validated and tested for reliability. The internal consistency of QEAT was found to be 0.78 using K-R 20. An additional test of temporal stability was done using test re-test method and Pearson product moment was used to determine the correlation coefficient which was established at 0.80 . Data collected were analysed using mean and standard deviation for the research questions while ANCOVA was used in testing the null hypothesis at 0.05 level of significance. The result showed that students taught quantitative economics contents using TAI had higher mean achievement score than those exposed to STAD instructional technique. Male students had slightly higher mean achievement score than the female students in quantitative economics contents. There was no significant interaction effect of STAD, TAI and gender on student's mean achievement in quantitative economics contents. Based on the findings, it was concluded that TAI is more efficacious than, STAD in enhancing student's achievement in secondary school quantitative economics contents. It was recommended, among other things that TAI should be adopted in teaching secondary school quantitative economics contents. To achieve this, the Ministry of Education should collaborate with educational institutions and organize workshops and sem inars for economics teachers on the inherent skills and procedures for using the TAI technique in quantitative economics contents delivery.
\end{abstract}

Key words: Economics, achievement, STAD, TAI, quantitative economics, procedures

\section{INTRODUCTION}

Economics is concerned with how effective individuals make rational decisions concerning the use of resources. This definition aligns with the view by Campbell and Stanley (2005) who opined that economics is a social science subject concerned with the efficient use of scarce resources to achieve the maximum satisfaction of economic wants. Ayers and Collinge (2005) refer to economics as a subject that explains how to make good choices. This definition of economics as primarily how to make choices is vague. It would be better to assume that economics examines the result of choices made, since, making choices requires some degree of rationality. Operationally, economics as a discipline provides information on how people choose to use limited or scarce resources in an attempt to satisfy unlimited wants.

Economics is an important school subject in the society. This justifies why it was included as one of the elective subjects at the senior secondary school level in Nigeria. The learning of economics at this level allows students to rationally engage in economic tasks and activities in line with the envisaged goals of the subject. The senior secondary school economics curriculum is therefore, predicated on the principle of equipping students with basic knowledge and skills considered necessary for appreciating the nature of economic problems in the society. This is to adequately prepare them for the inherent challenges in the Nigerian

Corresponding Author: Benedict Ejiofor Ugwuanyi, Department of Social Science Education, University of Nigeria, Nsukka, 410001 PMB, Enugu State, Nigeria 


\section{J. Eng. Applied Sci., 14 (Special Issue 5): 8912-8920, 2019}

economy. The philosophy of the senior secondary school economics curriculum as stated by Federal Ministry of Education (2008) is to present economics as a subject that has relevance in everyday life and activities in order to prepare students for entrepreneurial endeavours in future.

The realization of this philosophy is necessary because economics provides a mechanism for looking at possible ways to optimize resource utilization in order to reduce wastages. The actualization of the importance of economics is dependent on the way its contents are delivered. Facilitating the process of knowledge transmission in economics demands that economics teachers should apply appropriate instructional methods that best suit specific objectives and level of outcome. Effective instructional method enhances learning. Thus, the term instructional method refers to the general principles, pedagogy and management strategies used for classroom instruction. When appropriate instructional methods are used effectively to accomplish a task, it can motivate students and help them focus attention organize information for understanding (Albert, 2002). However, many teaching practitioners widely apply teacher-centred methods to impart knowledge to learners comparative to studentcentred methods. The teacher-centred method does not take cognizance of the student's learning differences; participation or involvement in teaching and learning. In teacher-centered method, the teacher talks while the students listens. Therefore, changing the focus of the classroom from the teacher-centred to the learners centred has far-reaching implications on how we teach economics to make it a more interesting subject where concepts are understood deeply, so that, they can be applied.

One effective instructional method that can be used which accommodates a wide range of student differences is cooperative learning method. Cooperative learning refers to a method of instruction that organizes classroom instruction into groups of 2-6 students who research together to reach a common goal. There are different techniques of cooperative learning. They include; Student's Team Learning (STL) (such as student team achievement division), Jigsaw Reading, Group Investigation (GI), Learning Together (LT), Team Accelerated Instruction or Team Assisted Individualization (TAI), among others. This study adopted STAD and TAI.

The Student Team Achievement Division (STAD) was developed by Slavin and Karweit (1984). Student Team Achievement Division (STAD) is a cooperative-learning strategy in which small groups of learners with different levels of ability work together to accomplish a shared learning goal (Majoka et al., 2010). $\mathrm{STAD}$ is one of the techniques of cooperative learning in which students are divided into groups of 4-5 members. The teacher presents a lesson and then students work together within their teams to make sure that all team members have mastered the lesson. Finally, all students take individual quizzes on the material at which time they may not help one another. The average of the student's score in each group is the score of the STAD group. Student's quiz scores are compared to their own past averages and points are awarded based on the degree to which students meet or exceed their own earlier performance (Saniei and Ghadikolaei, 2015). Accordingly, the STAD groups are classified into good team, great team and super team with respect to their scores achieved at the end of each session (Tiantong and Teemuangsai, 2013). The best group is rewarded on the basis of individual improvement. The reward is given in different forms their names may be written on the bulletin board or they may be given certificates at the end of every week (Ishtiaq et al., 2015). STAD is considered a good strategy because as one of the cooperative learning techniques, it can raise student's motivation in learning by exchanging and sharing information, reinforcing each other, giving feedback and having the responsibility for their tasks in group work.

This technique was chosen because amongst other cooperative learning techniques, STAD is easy for teachers to apply and can be used to teach a variety of subjects from primary to university level. However, according to Majoka et al. (2010), STAD is effective for academic achievement in mathematics compared to traditional methods of teaching such as the lecture method. In this study, STAD technique was used to teach quantitative contents of economics, to determine its effect on student's achievement in quantitative contents of senior secondary economics in comparison with another cooperative technique, Team Accelerated Instruction (TAI).

Team Accelerated Instruction or Team Assisted Individualization Group (TAI) is another technique of cooperative learning used in this study. This is a method that has been found effective in facilitating performance in mathematics (Nneji, 2011). Thus, it could be applied in teaching quantitative economics contents which are mathematical oriented. The TeamAccelerated Instruction (TAI) incorporates cooperative learning and individualized instruction. TAI allows children to progress on an individual basis and it teaches cooperation by forming teams of students who can help each other to achieve team goals. TAI is a technique where students take a placement test at the beginning of the programme and begin instruction at an appropriate place in an individualized sequence. The placement test is used to divide the students into groups of 4. Students proceed at different units depending on their ability level. There are skill practice pages, formative quizzes and test, contained in worksheets which are answered, so that, a class monitor may score the test. 


\section{J. Eng. Applied Sci., 14 (Special Issue 5): 8912-8920, 2019}

TAI instructional technique is programmed for 4 weeks. Students earn points with their team members by passing tests, handing in assignments, completing homework, understanding the concepts and completing their work. Students mark each other's assessment and those students assigned as monitors will correct test and check homework. The management functions of securing materials, checking student papers and scoring tests are the responsibility of the students. At the end of the fourth week, the teacher presents the whole content studied and resolves all confusions of students on issues resulting from the lessons. In TAI, students encourage and help one another to succeed. Individual accountability is assured because the only score that counts is the final test score and students take final tests without teammate's help. Students have equal opportunities for success because they all have prior knowledge of the lesson contents. An award is given at the end of the session to the team that performed higher by adding the points of individual students. TAI was developed to apply cooperative learning techniques to solve many of the problems of individualized instruction. TAI combines interactive instruction by teachers with cooperative team learning to accelerate the achievement of all students, maximize teaching and learning time, enhance student motivation and positive attitudes toward quantitative subjects and improve student's social interactions (Istikha, 2015). This position is explained better by Social Cognitive Development theory by Vygotsky and Cole (1978) which states that learning is socially constructed from cooperative efforts to learn, understand and stresses that reciprocal interaction among students around suitable academic tasks, enhances growth in knowledge of concepts and critical thinking skills. TAI is known to enhance student's achievement in mathematics and it was chosen for this study because economics is mathematical in nature and it is expected that this technique may also help accelerate student's achievement in quantitative economics content which student finds difficult.

Academic achievement represents performance outcomes that indicate the extent to which students have accomplished specific goals of instructional in teaching and learning process. It refers to a teaching-learning outcome or instructional outcome. Academic achievement in economics has been poor over the years (Anonymous., 2016). This is because students encounter some difficulties in learning economics despite its importance (Adu et al., 2014). This difficulty may be the reason for the poor achievement of student in economics. This perceived difficulty could be attributed to both the structure and abstract nature of some quantitative or mathematical contents of senior secondary school economics which tend to discourage students. The difficulty students encounter in learning these quantitative contents of economics could be attributed also to poor teaching of the mathematical or quantitative contents of the subject (Shiller, 2013).

The above position is supported by the poor performance of candidates in economics over the years in the West African Senior School Certificate Examination. West African Examinations Council (WAEC) Chief Examiner's Report from 2010 through 2016 indicated that the performance of candidates in economics was indeed poor. The common weakness manifested in candidate's scripts included poor grammatical expression, scanty explanation of points, poor knowledge of drawing graphs and simple calculation, lack of manipulative skill (Anonymous, 2016). In line with the above reports, Oyadeji and Fonska as cited by Adu et al. (2009) posit that one pertinent factor which could influence student's achievement in senior secondary school economics is student's quantitative ability. Quantitative ability entails student's ability to apply knowledge of mathematical concepts and principles, to demonstrate flexibility in thinking, make a correct generalization and compare mathematical expression (Adu et al., 2009). Quantitative contents in the senior secondary school economics curriculum include; basic tools of economic analysis, the concept of demand and supply, production possibility curve, cost and revenue concept, price determination, elementary treatment of utility theory, balance of payment, national income accounting, regression equation and measure of dispersion among others. To learn or teach these quantitative contents, there is a need for quantitative ability by the students and teachers, respectively. However, this is not usually demonstrated by the students probably due to their poor mathematical background or by the teacher's ineffectiveness as a result of the wrong choice of instructional method (Adu and Ayeni, 2004). Adu et al. (2009) reported that teachers who teach economics in Nigerian secondary schools use the lecture method. This has implications for the economics teacher's ability to assist students to engage effectively in problem-solving activities in economics lessons. Adu and Ayeni (2004) opine that the lecture method does not give students the opportunity to ask questions or participate in the learning process. Thus, the attainment of senior secondary school economics objectives depends on the teachers and other related instructional variables.

Another variable that influences student's achievement is gender. Gender refers to cultural and social construct which describes or analyses the roles, expectations, behaviours, characteristics and attributes of male and female based on their biological sex (Unity and Igbudu, 2015). It refers to the role assigned to male and female by the society. The issue of academic achievement with respect to gender has generated considerable interest 
in economics. Goldin et al. (2006) stated that female students outperform male students in quantitative economics. Niederle and Vesterlund (2010) reported that there is a slight difference between male and female student's achievement in economics. Thus, based on the above inconclusive position on gender difference in achievement gender was included as one of the variables of the study. From the foregoing background, this study determined the comparative effectiveness of STAD and TAI on student's achievement in senior secondary school quantitative contents of economics curriculum.

Statement of the problem: It is the expectation of stakeholders in education that students perform better in economics given its relevance in decision making regarding the rational use of resources. However, studies have shown that students seem to have wrong impression that economics is difficult. This may have affected their achievement in the West African School Certificate Examination in economics. Thus, the West African Examination Council Chief Examiner's reports of, 2010, through 2016 show that achievement in economics is poor in the West African Certificate Examination (WASSCE). The common weaknesses manifested in the candidate's scripts as reported by the WAEC Chief examiner's reports were poor grammatical expression, scanty explanation of points inadequate knowledge of drawing and analysis of graphs, simple calculation and lack of manipulative skills. These deficiencies could be attributed to student's negative attitude towards mathematical contents as well as ineffectiveness on the part of teachers due to the use of poor instructional methods and techniques. This ineffectiveness could result in low student-teacher interaction due to the use of routine conventional teaching methods that do not encourage student's participation in the teaching-learning process. Against this backdrop, this study compared the relative effectiveness of STAD and TAI in enhancing student's achievement in quantitative contents of senior secondary school economics.

Research questions: The following research questions guided the study. What are the mean achievement scores of students taught quantitative contents of senior secondary school economics using STAD and TAI?

What are the mean achievement scores of male and female students taught quantitative contents of senior secondary school economics using STAD and TAI?

What are the interaction effects of STAD, TAI and gender on student's achievement in quantitative contents of senior secondary school economics?

Hypothesis: The following null hypothesis guided the study and were tested at 0.05 level of significance.
- $\mathrm{H}_{01}$ : there is no significant difference in the mean achievement scores of students taught quantitative contents of senior secondary economics using STAD and TAI

- $\mathrm{H}_{\mathrm{O} 2}$ : there is no significant difference in the mean achievement scores of male and female student's taught quantitative contents of senior secondary economics using STAD and TAI

- $\mathrm{H}_{03}$ : there is no significant interaction effect of STAD, TAI and gender on student's mean achievement in quantitative contents of senior secondary school economics

\section{MATERIALS AND METHODS}

The study adopted a quasi-experimental design, specifically, non-randomized, pre-test, post-test control group design. The study was carried out in secondary schools in Nsukka Local Government Area of Enugu State, Nigeria. The population of the study consisted of eight thousand nine hundred and sixty-six senior secondary school students from thirty public secondary schools in Nsukka Local Government Area of Enugu State out of which 4,659 are females and 4,307 are males in the 2015/2016 academic session. The sample size for the study consisted of all the 186 SS II students in eight intact classes which were drawn from four co-educational schools in Nsukka Local Government Area in the 2015/2016 academic session. Purposive sampling was used to sample only co-educational schools due to gender variable. Simple random sampling was used to sample four schools out of the co-educational schools. Two intact classes each from the four public secondary schools were drawn randomly, making a total of eight intact classes. The four intact classes drawn from two schools received STAD treatment and the other four intact classes received TAI treatment. The intact classes were assigned to experimental groups randomly.

Quantitative Economics Achievement Test (QEAT), developed by the researchers based on the senior secondary school economics contents was used for data collection. The QEAT consists of 30 multiple choice quantitative economics contents items drawn from topics such as regression equation and measures of dispersion, cost concept, revenue concept and production possibility curve. The QEAT was structured to capture student's achievement before treatment and changes in their achievement after treatment. The instrument for data collection was subjected to both face and content validation. The face validation of the instrument was done by three experts. The corrections they gave were reflected 
in the final production of the instrument. The content validity of the instrument was determined using the table of specification.

To determine for internal consistency of the instrument, a single administration of the QEAT was administrated to 30 students in a school outside the study area. The reliability of QEAT was established using Kuder-Richardson's formula 20 (KR-20). The analysis yielded a reliability index of 0.78 . To determine the temporal stability of the instrument, a test-retest method was used at an interval of 2 weeks. The two sets of scores obtained on the two occasions were correlated using Pearson product moment and a correlation coefficient of 0.81 was established which shows a high correlation of the two scores.

The following procedures were undertaken in carrying out the quasi-experiment. The researchers trained regular economics teachers to be used for the study on the use of STAD and TAI. After the training, the research assistants administered the Quantitative Economics Achievement Test (QEAT) as a pre-test to the students. The pre-test instruments were retrieved marked, scored and recorded by the assistants and handed over to the researchers for further use. Thereafter, the experiment commenced. The first experimental group were taught using STAD technique while the second experimental group were taught using TAI technique. The period of teaching in each of the group was 4 weeks.

After the 4 weeks of the experiment, the research assistants administered the Quantitative Economics Achievement Test (QEAT) as post-test. The post-test questions were the same as the pre-test questions already answered by the students, except that the post-test questions were shuffled. At the end of the post-test, the student's scripts were collated, marked and recorded by the research assistants before they were handed over to the researchers for data analysis. Mean and standard deviation were used to answer the research questionsthat guided the study. Hypothesis were tested at $\mathrm{p}<0.05$ level of significance using Analysis of Covariance (ANCOVA). ANCOVA is used in quasi-experimental research of non-equivalent group to reconcile initial group difference among the research subjects.

\section{RESULTS AND DISCUSSION}

Research question one: What are the mean achievement scores of students taught quantitative contents of senior secondary school economics using STAD and $\mathrm{TAI}$ ?

Table 1 shows that the students who were taught quantitative contents of economics using STAD had pre-test mean achievement score of 54.38 and post-test mean achievement score of 66.62. Those who were taught using TAI had pre-test mean achievement score of 47.95 and post-test mean achievement score of 70.72 .
Table 1: Mean and standard deviation of achievement scores of students taught quantitative contents of economics using STAD and TAI

\begin{tabular}{lcccccc}
\multicolumn{3}{c}{ STAD and TAI } \\
& Pre-test & & \multicolumn{2}{l}{ Post-test } \\
Groups & $\mathrm{N}$ & Mean & SD & Mean & SD & Mean gain \\
\hline STAD & 74 & 54.38 & 10.91 & 66.62 & 13.30 & 12.24 \\
TAI & 112 & 47.95 & 13.95 & 70.72 & 13.00 & 22.77 \\
\hline
\end{tabular}

Table 2: Analysis of covariance of the effect of STAD and TAI on student's achievement in quantitative contents of secondary school economics

\begin{tabular}{|c|c|c|c|c|c|}
\hline Sources & $\begin{array}{c}\text { Type III sum } \\
\text { of squares }\end{array}$ & df & $\begin{array}{l}\text { Mean } \\
\text { square }\end{array}$ & F-values & Sig. \\
\hline $\begin{array}{l}\text { Corrected model } \\
\text { model }\end{array}$ & $914.101^{a}$ & 4 & 228.525 & 1.312 & 0.267 \\
\hline Intercept & 48987.671 & 1 & 48987.671 & 281.258 & 0.000 \\
\hline Pre-test & 28.286 & 1 & 28.286 & 0.162 & 0.687 \\
\hline Group & 652.405 & 1 & 652.405 & 4.746 & 0.035 \\
\hline Gender & 148.853 & 1 & 148.853 & 0.855 & 0.356 \\
\hline Group & 13.348 & 1 & 13.348 & 0.077 & 0.782 \\
\hline *Gender & & & & & \\
\hline Error & 31525.345 & 181 & 174.173 & - & - \\
\hline Total & 920333.000 & 186 & - & - & - \\
\hline $\begin{array}{l}\text { Corrected } \\
\text { Total }\end{array}$ & 32439.446 & 185 & - & - & - \\
\hline
\end{tabular}

*Significant values

Mean gain scores of 12.24 and 22.77 for the two groups, respectively, show that the students who were taught using TAI achieved higher than their counterparts who were taught using STAD. Also, the table show that the STAD group had a standard deviation score of 10.91 before the treatment and 13.30 after the treatment indicating that the scores are widely spread for STAD than for TAI which recorded a standard deviation of 13.95 for pre-test and 13.00 for post-test indicating that the widely spread scores in the pre-test closed up nearer to the mean as compared to the STAD counterparts after treatment.

- $\mathrm{H}_{\mathrm{O}}$ : there is no significant difference in the mean achievement scores of students taught quantitative contents of secondary school economics using STAD and TAI

Table 2 shows that the probability associated with the calculated value of $F(4.75)$ for the effect of STAD and TAI on student's achievement in quantitative contents of economics is 0.04 . Thus, since, the probability value of 0.04 is $<0.05$ level of significance $(p<0.05)$, the null hypothesis was rejected. The inference drawn was that there is a significant difference in the mean achievement scores of students taught quantitative contents of economics using STAD and those taught using TAI in favour of those taught quantitative contents of economics using TAI. This implies that TAI is relatively more efficacious in enhancing student's achievement in quantitative economics contents than the STAD. 
J. Eng. Applied Sci., 14 (Special Issue 5): 8912-8920, 2019

Table 3: Mean and standard deviation of achievement scores of male and female students taught quantitative contents of senior secondary school economics using STAD and TAI

\begin{tabular}{lllllr}
\hline & & Pre-test & \multicolumn{3}{c}{ Post-test } \\
Groups/Genders & $\mathrm{n}$ & Mean & $\mathrm{SD}$ & Mean & SD \\
\hline STAD & & & & & \\
Male & 26 & 52.54 & 10.10 & 68.19 & 13.19 \\
Female & 48 & 55.38 & 11.30 & 65.77 & 13.42 \\
TAI & & & & & \\
Male & 39 & 44.79 & 14.77 & 71.51 & 9.88 \\
Female & 73 & 49.63 & 13.30 & 70.30 & 14.45 \\
\hline
\end{tabular}

Research question two: What are the mean achievement scores of male and female students taught quantitative contents of senior secondary school economics using STAD and TAI.

Table 3 reveals the mean achievement scores of male and female students in quantitative economics contents before and after the experiment. It shows that male students in STAD group had pre-test mean achievement score of 52.54 and a post-test mean achievement score of 68.19 while their female counterparts had pre-test mean achievement score of 55.38 and a post-test mean achievement score of 65.77. Mean gain scores of 13.19 and 13.42 for the male and female students, respectively, indicate that male students had higher mean achievement score than their female counterparts. The Table also shows that male students in TAI group had pre-test mean achievement score of 44.79 and post-test achievement score of 71.51 with a mean gain of 9.88 while their female counterpart had pre-test mean achievement score of 49.63 and post-test achievement score of 70.30 with a mean gain of 14.45. The Table also shows that the standard deviation for male students in STAD for pre-test was 10.10 implying a wider spread of scores from the mean which was widened up after treatment at 13.19. Also, the standard deviation for female students at pre-test was 11.30 which widened farther from the mean after treatment to 13.42. In TAI group, the male student had a standard deviation of 14.77 implying a wider spread of score which closed up after treatment at 9.88 for post-test while their female counterpart had 13.30 showing a wider spread of mean score which widened farther after treatment at 14.45 for post-test. Irrespective of the fact that both the STAD and TAI enhances student's achievement in quantitative contents of economics, the findings indicate that male and female students in TAI group had better achievement compared to male and female students in STAD group.

- $\mathrm{H}_{\mathrm{O} 2}$ : there is no significant difference in the mean achievement scores of female and male students in quantitative contents of economics

Table 2 shows that the probability associated with the calculated value of $\mathrm{F}(0.86)$ for the influence of gender on
Table 4: Mean and standard deviation of achievement scores of students for the interaction effect of STAD, TAI and gender on student's mean achievement score in quantitative contents of senior secondary school economics

\begin{tabular}{lccclr}
\hline \multicolumn{3}{c}{ Pre-test } & & \multicolumn{2}{l}{ Post-test } \\
Groups/Genders & n & Mean & SD & Mean & SD \\
\hline STAD & & & & & \\
Male & 26 & 52.54 & 10.10 & 68.19 & 13.19 \\
Female & 48 & 55.38 & 11.30 & 65.77 & 13.42 \\
TAI & & & & & \\
Male & 39 & 44.79 & 14.77 & 71.51 & 9.88 \\
Female & 73 & 49.63 & 13.30 & 70.30 & 14.45 \\
\hline
\end{tabular}

student's achievement in quantitative contents of economics is 0.36 . Since, the probability value of 0.36 is $>0.05$ level of significance $(p>0.05)$, the null hypothesis was accepted. Thus, there is no significant difference in the mean achievement scores of male and female students in quantitative contents of economics.

Research question three: What are the interaction effect of STAD, TAI and gender on student's mean achievement score in quantitative contents of senior secondary school economics?

Table 4 shows that male students who were exposed to STAD had a pre-test mean achievement score of 52.54 and a post-test mean achievement score of 68.19 while the female students who were also exposed to STAD had a pre-test mean achievement score of 55.38 and post-test mean achievement score of 65.77. Similarly, male students who were exposed to TAI had a pre-test mean achievement score of 44.79 and a post-test mean achievement score of 71.51 while the female students who were also exposed to TAI had pre-test mean achievement score of 49.63 and post-test mean achievement score of 70.30. This by implication shows that both male and female students who were exposed to TAI had higher post-test mean achievement scores than the male and female students who were exposed to STAD. The improvement in the scores of the males and females in TAI experimental group over those of the males and females in the STAD group could be attributed to the effect of treatment alone and not from the interaction effect of instructional technique and gender. Also, it was shown in the table that there is a higher standard deviation for STAD group at 10.10 and 11.30 for male and female students, respectively, before treatment and higher standard deviation of 13.19 and 13.42 for male and female students, respectively, after treatment implying that the individual scores of the respondents are farther away from the mean after treatment. Also, for the TAI group, male students had a higher standard deviation of 14.77 in pre-test and 9.88 in post-test indicating that after the treatment, the scores became closer to the mean. This was different for the female students who had a standard deviation of 13.30 at the pre-test indicating a wider spread 


\section{J. Eng. Applied Sci, 14 (Special Issue 5): 8912-8920, 2019}

of scores and a standard deviation 14.45 after treatment implying a more farther away of the scores from the mean. Thus, both STAD and TAI do not interact with gender to influence student's achievement in quantitative economics contents.

- $\mathrm{H}_{\mathrm{O}}$ : there is no significant interaction effect of the STAD, TAI and gender on student's mean achievement in quantitative contents of secondary school economics

Table 2 shows that the calculated value of $F(0.08)$ for the interaction effect of STAD, TAI and gender on student's mean achievement in quantitative contents of economics has an associated probability value of 0.78 . Thus, there is no significant interaction effect of STAD, TAI and gender on student's mean achievement in quantitative contents of economics. This is due to the fact the probability value of 0.78 is $>0.05$ level of significance $(\mathrm{p}>0.05)$.

Discussion of findings: Evidence from this study shows that students who were taught economics using TAI obtained a higher post-test mean achievement score than those taught the same quantitative contents of secondary school economics using STAD. The difference between these mean scores was statistically significant as shown in the result presented in Table 2 . Hence, the null hypothesis was rejected meaning that there is a significant difference in the mean achievement scores of students taught quantitative contents of secondary school economics using STAD and TAI in favour of those taught quantitative economics content with TAI. The finding of this study is in line with those by Rusli, Nneji (2011), Gambari and Yusuf (2014) on the effectiveness of $\mathrm{TAI}$ in teaching mathematics-related disciplines such as Physics, Mathematics and Basic Science. For instance, Rahman et al. (2016) in their study which examined which cooperative learning models (TAI and STAD) is suitable for improving students learning outcomes in mathematics, found out that the use of TAI led to better achievement compared to STAD. This study has proven that it is the same in economics. The result of this study also reveals that even though, students find economics, so, quantitatively oriented and difficult and so perform poorly as reported in the works by Fonska by Adu et al. (2009); Adu and Oshati (2014) achievement can be improved when the right approach is applied.

The findings of this study with respect to the effect of gender on student's achievement in quantitative economics contents (when both techniques are used) show that male students had higher mean achievement score than female students. This finding contradicts Kuziemko who found out that female students outperform male students in quantitative economics. However, the finding is in line with the postulations by Niederle and Vesterlund (2010), Bridges and Casavant (1999) who documented that there is a slight achievement difference between male and female students in quantitative contents of secondary school economics, although, they did not show the direction of the difference. The finding also indicated that the difference in the mean achievement scores of male and female students is statistically not significant. Hence, the null hypothesis that there is no significant difference in the mean achievement scores of male and female students in quantitative contents of economics was accepted. The findings of the present study conform to the findings by Njoroge and Githua (2013), Ajai and Imoko (2015) on mathematics achievement with respect to gender. In their study, female and male students did not significantly differ in mathematics achievement. This can be explained because economics and mathematics have the same quantitative orientation and so, what applies to mathematic may apply also to economics. Therefore, achievement in economics irrespective of the pedagogy used did not favour either gender as Mackintosh by Unity and Igbudu (2015) stated, rather the achievement of both female and male students can be enhanced when appropriate pedagogy is applied in teaching economics. This finding conforms with the tenets of self determination theory (Deci and Ryan, 1995) which assumes that all students no matter their age gender, socio-economic status and so on possess inherent growth tendencies. Therefore, these growth tendencies exist in both males and females but could need an effective pedagogy like TAI to be re-awaken or aroused forbetter academic achievement.

The findings on the interaction effect of STAD, TAI and gender on student's mean achievement scores in quantitative contents of economics, reveal that both male and female students who were exposed to TAI had higher post-test mean achievement scores than the male and female counterparts who were exposed to STAD. The study also established that there is no significant interaction effect of STAD, TAI and gender. Findings reveal that the interactive effect of STAD, TAI and gender is not statistically significant.

Even though the findings show that male students had slightly better achievement score than female students in quantitative contents of secondary school economics, the difference is not significant. From the findings, students exposed to TAI had better achievement than, those exposed to STAD with respect to gender. However, the difference is still not significant. These findings are in line with the studies by Njoroge and Githua (2013), Ajai and Imoko (2015), Yusuf et al. (2015) which claim that achievement with respect to gender does not differ significantly. This implies according to Ajai and Imoko (2015) that enhanced achievement in mathematics is a function of orientation and not necessarily gender-based. This also means that male and female students are capable of competing and collaborating in mathematics and that their enhanced achievement could be due to the technique employed. The result could also imply 
that both TAI and STAD are innovative techniques and this may have resulted in a slight difference in achievement.

\section{CONCLUSION}

Student's exposed to TAI achieved significantly higher than those exposed to STAD in quantitative contents of secondary school economics. This means that the TAI prove more efficacious to STAD in promoting student's achievement in quantitative economics contents. Gender had no significant influence on student's achievement in quantitative contents of secondary school economics. The interaction effect of STAD, TAI and gender on student's achievement in quantitative contents of senior secondary school economics were not statistically significant. This means that the improvement in student's achievement in quantitative contents of senior secondary school economics was due to the treatment applied not on gender.

\section{RECOMMENDATIONS}

The following recommendations are hereby made based on the findings and implications of the study: the National University Commission (NUC), National Commission for Colleges of Education (NCCE) and other bodies responsible for the review of higher education curriculum should include TAI in pedagogical courses in educational institutions. The essence is to equip pre-service teachers to use such a technique to enhance student's achievement in quantitative economics contents on graduation.

Curriculum planners for secondary schools such as the Nigerian Educational Research and Development Council (NERDC) should incorporate the use of TAI as an effective technique in teaching quantitative economics in the next review of the curriculum.

\section{ACKNOWLEDGEMENT}

The researchers are very grateful to the study respondents for filling out the questionnaire honestly.

\section{REFERENCES}

Adu, E.O. and A.O. Ayeni, 2004. An Appraisal of Trends in Performance of Students in Economics at the SSCE in Ibadan North LGA of Oyo State (1994-1998). In: Teacher's Mandate on Education and Social Development in Nigeria, Elaturoti, D.F. and K. Babarinde (Eds.). Sterling-Horden Publishers, Ibadan, Oyo State, Nigeria, pp: 129-141. Adu, E.O. and T. Oshati, 2014. Psychological variables as correlate of student's academic achievement in secondary school Economics in Oyo State, Nigeria. J. Psychol., 5: 125-132.
Adu, E.O., O. Galloway and B.C. Olaoye, 2014. Introduction to social studies: A basic text for tertiary institution students. Educational Research and Study Group, Ibadan, Nigeria.

Adu, E.O., S.A. Ojelabi and H. Adeyanju, 2009. Quantitative ability as correlates of student's academic achievement in secondary school Economics in Oyo State, Nigeria. Afr. Res. Rev., 3: 322-333.

Ajai, J.T. and B.I. Ipmoko, 2015. Gender differences in mathematics achievement and retention scores: A case of problem-based learning method. Intl. J. Res. Educ. Sci., 1: 45-50.

Albert, I., 2002. Health and Life Skill Guide to Implementation (K-9). Albert Learning, Alberta, Canada,.

Anonymous, 2016. WACE E-learning. West African Examination Council, Lagos, Nigeria.

Ayers, R.M. and R.A. Collinge, 2005. Economics: Explore and study. Pearson Education, Upper Saddle River, New Jersey, USA.,

Bridges, D.E. and K.L. Casavant, 1999. Does gender, class standing and high school Economics influence student's Economic learning. Proceedings of the Annual Meeting on Western Agricultural Economics Association, July 11-14, 1999, Fargo, North Dakota, pp: 1-15.

Campbell, R.M. and L.B. Stanley, 2005. Economics Principles, Problems and Policies. McGrawHill/Irwin Publishers, New York, USA.,.

Deci, E.L. and R.M. Ryan, 1995. Human Autonomy: The Basis for True Self-Esteem. In: Efficacy, Agency and Self-Esteem, Kernis, M.H. (Ed.). Springer, Boston, Massachusetts, USA., ISBN:978-1-4899-1282-4, pp: 31-49.

Federal Ministry of Education, 2008. Senior secondary school Economics curriculum. Nigeria Education Research Development Council (NERDC), Abuja, Nigeria.

Gambari, I.A. and M.O. Yusuf, 2014. Effects of three cooperative learning strategies on the performance of secondary school students in physics. Chem. Bulg. J. Sci. Educ., 23: 1-23.

Goldin, C., L.F. Katz and I. Kuziemko, 2006. The homecoming of American college women: The reversal of the college gender gap. J. Econ. Perspect., 20: 133-156.

Ishtiaq, M., Z. Ali and M. Salem, 2015. The effects of Student Teams Achievement Division (STAD) on motivation of Saudi EFL adult learners. Intl. J. Lang. Educ. Appl. Ling., 3: 11-24.

Istikha, Y., 2015. The use of team accelerated instruction method to improve students reading comprehension of eleventh-grade students of SMA Muhammadiyah Plus Salatiga in the academic year of 2014/2015. BA Thesis, State Institution for Islamic Studies, Salatiga, Indonesia. 
Majoka, M.I., M.H. Dad and T. Mahmood, 2010. Student Team Achievement Division (STAD) as an active learning strategy: Empirical evidence from mathematics classroom. J. Educ. Sociology, 4: $16-20$.

Niederle, M. and L. Vesterlund, 2010. Explaining the gender gap in math test scores: The role of competition. J. Econ. Perspect., 24: 129-144.

Njoroge, J.N. and B.N. Githua, 2013. Effects of cooperative learning/teaching strategy on learners mathematics achievement by gender. Asian J. Soc. Sci. Humanities, 2: 567-576.

Nneji, L., 2011. Impact of framing and team assisted individualized instructional strategies students achievement in basic science in the North central zone of Nigeria. Knowl. Rev., 23: 1-8.

Rahman, A., A. Ahmar and R. Rusli, 2016. The influence of cooperative learning models on learning outcomes based on student's learning styles. World Trans. Eng. Technol. Educ., 14: $425-430$.

Saniei, A. and F.N. Ghadikolaei, 2015. The contribution of Student Teams-Achievement Divisions (STAD) to teaching English collocations to intermediate learners. Intl. J. Lang. Learn. Appl. Linguistic. World, 8: 125-133.
Shiller, R.J., 2013. Is economics a science?. Project Syndicate, Prague, Czechia. https://www. project-syndicate.org/commentary/robert-j-shilleron-whether-he-is-a-scientist.

Slavin, R.E. and N.L. Karweit, 1984. Mastery learning and students. Teams: A factional experiment in Urban General Mathematics classes. Am. Educ. Res. J., 21: 725-736.

Tiantong, M. and S. Teemuangsai, 2013. Student Team Achievement Divisions (STAD) technique through the moodle to enhance learning achievement. Intl. Educ. Stud., 6: 85-92.

Unity, O. and U. Igbudu, 2015. Influence of gender on students academic achievement in Government subject in public secondary schools in Oredo local government area of Edo State, Nigeria. J. Educ. Soc. Res., 5: 101-106.

Vygotsky, L.S. and M. Cole, 1978. Mind in Society: The Development of Higher Psychological Processes. Harvard University Press, Cambridge, Massachusetts, USA., ISBN:9780674576292, Pages: 159 .

Yusuf, Y.Q., Y. Natsir and L. Hanum, 2015. A Teacher's experience in teaching with Student TeamsAchievement Division (STAD) technique. Intl. J. Instruction, 8: 99-112. 